\title{
ATIVIDADES MIMÉTICAS E DISPOSITIVOS DE CONTROLE NO COLÉGIO AMERICANO BATISTA NO RECIFE
}

\author{
MIMETIC ACTIVITIES AND CONTROL DEVICES IN THE \\ AMERICAN BAPTIST COLLEGE IN THE RECIFE
}

\section{ACTIVIDADES MIMÉTICAS Y DISPOSITIVOS DE CONTROL EN EL COLEGIO AMERICANO BATISTA EN RECIFE}

\author{
Edilson Fernandes SOUZA ${ }^{\mathrm{I}}$ \\ José LUÍs SIMÕeS ${ }^{\mathrm{I}}$ \\ Marcos AndRé Nunes Costa ${ }^{\text {II }}$ \\ 'Universidade Federal de Pernambuco (UFPE), Recife/PE - Brasil. \\ "Universidade Federal Rural de Pernambuco (UFRE), Recife/PE - Brasil.
}

\begin{abstract}
Resumo À luz da teoria eliasiana, o artigo apresenta as atividades miméticas incentivadas no Colégio Americano Batista, criado na cidade do Recife, em 1906, e os seus dispositivos institucionais publicados para orientar e controlar os estudantes no cotidiano educacional. A análise concentra-se em fontes como o Prospecto de 1918, o Regulamento Disciplinar de 1920 e o Decálogo de 1925. Constata-se que a Instituição Educacional Batista tinha como objetivo o desenvolvimento do self-control em seus estudantes, permitindo jogos parlamentares e atléticos e proibindo, simultaneamente, impulsos contrários à Lei do Governo Próprio e o Cavalheirismo no Jogo. Assim, o referido Colégio buscava afirmação de membros outsiders no campo educacional e cristão protestante.

Palavras-chave: Autocontrole; Atividades miméticas; Colégio batista.
\end{abstract}

Abstract In the light of the Eliasian theory, the article presents the mimetic activities encouraged in the American Baptist College, created in the city of Recife in 1906 and its institutional devices published to guide and control students in educational daily life. The analysis focuses on sources such as the 1918 Prospectus, the Disciplinary Regulations of 1920 and the Decalogue of 1925. It is noted that the Baptist educational institution aimed at developing self-control in its students, allowing parliamentary and athletic games, Same 
time prohibiting impulses contrary to the law of the Own Government and Chivalry in the Game. Thus, the said College sought affirmation of outsiders members in the educational and Protestant Christian field.

Key-words: Self-Control; Mimetic activities; Baptist college.

Resumen A la luz de la teoría eliasiana, el artículo presenta las actividades miméticas incentivadas en el Colegio Americano Batista, creado en la ciudad de Recife en 1906 y sus dispositivos institucionales publicados para orientar y controlar a los estudiantes en el cotidiano educativo. El análisis se concentra en fuentes como el Prospecto de 1918, el Reglamento Disciplinario de 1920 y el Decálogo de 1925. Se constata que la institución educativa bautista tenía como objetivo el desarrollo del self-control en sus estudiantes, permitiendo juegos parlamentarios y atléticos, $\mathrm{Al}$ mismo tiempo prohibiendo impulsos contrarios a la ley del Gobierno propio y al Caballerismo en el Juego. Así, el referido Colegio buscaba afirmación de miembros externos en el campo educativo y cristiano protestante.

Palabras clave: Autocontrole; Actividades miméticas; Colegio batista.

\section{INTRODUÇÃo}

Oportuno e necessário, este dossiê procura reverberar pesquisas que têm se inspirado, há algum tempo, nas teorias de Norbert Elias, tendo por foco empírico a educação no Brasil. Um país com múltiplos matizes étnico-raciais e das mais diversificadas tendências religiosas, não poderia deixar de produzir investigações a partir da síntese eliasiana. Desse modo, este artigo se insere no campo da história da cultura desenvolvida no interior da escola e tem por objetivo identificar e analisar alguns dispositivos de permissão e controle desenvolvidos pelo Colégio Americano Batista, sediado na cidade do Recife.

O tema educação e religião é revestido de considerável interesse em vários campos científicos e, conforme Cordeiro (2005), no século XIX, católicos e metodistas disputaram projetos educacionais na perspectiva de uma civilização cristã no Brasil, porque em sua análise "muitos líderes e pensadores eclesiásticos acreditavam que a vinda do Reino de Deus se daria depois que a civilização cristã fosse implantada e que a cristianização da sociedade seria, portanto, uma preparação para a vinda do Reino de Deus" (CORDEIRO, 2005, p. 117).

$\mathrm{Na}$ disputa de projetos educacionais, à figuração protestante é resguardada um capítulo especial por meio dos missionários, sobretudo, os norte-americanos. Calvani (2009), por exemplo, analisa o projeto educacional dos protestantes, situando o leitor acerca da criação de escolas no Brasil por iniciativa dos batistas, o que possibilita compreender os processos sociais relacionados à fé, pensamentos e práticas civilizacionais por intermédio da escolarização.

Nesse contexto, o Colégio foi criado pelo missionário norte-americano Dr. William Henry Canadá, que iniciou suas atividades em 15 de janeiro de 1906. Segundo Perruci et al. (2007), essa é uma data reconhecida oficialmente pela Convenção Batista Brasileira e, 
desde o seu início, vem cumprindo com obrigações em vários níveis de ensino. Em 1918, por exemplo, mantinha o ensino primário, intermediário e secundário, além do curso de Madureza, que, após quatro anos, era concedido o diploma de bacharel em Ciências e Letras, conforme consta no Regulamento aprovado pela instituição em 1920.

\section{OS DISPOSITIVOS DE ANÁLISE: AUTORES E FONTES}

O Colégio Americano Batista é uma instituição centenária, onde intelectuais estudaram o Jardim da Infância, por exemplo, Gilberto Freyre, em 1908, e, apesar dos cem anos de existência, analisaremos fontes que foram produzidas numa paisagem até 1925 . O período é necessário para compreendermos a dinâmica estabelecida na instituição a partir dos ensinamentos de orientação religiosa, como a utilização da Bíblia, bem como a criação de instrumentos com a finalidade de disciplinar os estudantes em variadas práticas educativas.

Nessa paisagem de 1925, o colégio funcionava recebendo estudantes no internato, semi-internato e externato, e estava em plena atividade educacional com vários níveis de ensino, como o Jardim da Infância, uma das primeiras modalidades desde o início e foi considerado o primeiro criado no Estado de Pernambuco, o ensino Primário, Complementar, Gynasial, Comercial, Normal e a Escola de Música.

Esses são elementos importantes para compreendermos o impulso do saber escolarizado impresso pelos batistas em Pernambuco, conforme consta de maneira significativa na historiografia consultada em ampla discussão acerca da política de ler e escrever, do processo de escolarização, dos processos educacionais e impressos produzidos pelos batistas, facilmente observados em Perruci et al. (2007), Anjos (2013), Costa (2014), Sellaro (1987) e, sobretudo, Silva (2009), que analisa a educação fortemente representada na imprensa protestante.

Além desses autores, que ajudam a pensar na historiografia local, de proximidade com o objeto, outros pesquisadores, situados no interior do Simpósio Internacional de Processo Civilizador, que nos orientam nesse dossiê, ajudam a pensar na relativa densidade que o tema resguarda do ponto de vista da teoria eliasiana, como Oliveira (2009), que fala da abertura de escolas para moças a partir do movimento de reforma religiosa e o papel social destinado à mulher em longo prazo e suas relações de interdependência e de poder.

Por sua vez, Sarat e Sarat (2007) analisam os registros e o olhar outsider dos missionários protestantes sobre o Brasil, que acreditavam na promoção civilizadora de sua permanência em nosso território. E Martins e Cardoso (2005) tratam de imigrantes protestantes batistas norte-americanos e o desenvolvimento de tecnologias na perspectiva civilizacional, para citar apenas alguns na abordagem sócio-histórica.

Esses autores, entre outros, demonstram conhecimento razoável da iniciativa dos batistas e suas prospecções educacionais Brasil afora, seja em artigos, livros, dissertações ou teses de doutoramento, cujos escritos nascem, por vezes, no interior dos próprios princípios religiosos, especialmente nos escritos de Perruci et al. (2007), que tratam com saudosismo as experiências educacionais da instituição batista, objeto deste artigo. 
Por se tratar de uma publicação do centenário do Colégio Americano Batista, a autora e os colaboradores pretendem mostrar, em suas 418 páginas, as experiências lembradas por estudantes, professores, gestores e religiosos. Mesmo de forma descritiva, podemos encontrar vários documentos que integram a instituição, como o Regulamento Disciplinar, decretos, depoimentos, fotografias, entre outros. São documentos que analisados de maneira mais criteriosa podem revelar um cotidiano institucional tecido numa trama estabelecida entre a sociabilidade, a educação e a fé.

Do ponto de vista de consenso, podemos pensar na historiografia da educação em que “os impressos (jornais, livros, livretos, etc.) tiveram um papel importante na difusão do protestantismo no Brasil" (SILVA, 2009, p. 66). Aliás, a tipologia ou a massa documental presente em diferentes instituições protestantes revigoram entre o despertar e difusão da fé e o desenvolvimento moral a partir da leitura de textos bíblicos, ainda que para as crianças e analfabetos existisse um cuidado especial no início do processo de evangelização nas primeiras décadas do século XX, conforme Silva (2009).

De qualquer modo, não é possível desprezar a massa documental que essa literatura revela e, até certo ponto, a preocupação no registro e repositório de memória das instituições educativas semelhantes ao nosso objeto de estudo. Assim, ao tratar deste objeto, sempre estaremos diante de uma farta documentação encontrada não só no repositório do Colégio Americano Batista, no Arquivo Público de Pernambuco, como também expressa na historiografia que já possui relativo consenso, considerando o acervo e os aspectos essenciais no resguardo da memória institucional, obviamente, nem sempre de fácil acesso.

A tipologia documental utilizada neste artigo poderia ser bastante variada entre fotografias, prospectos e outros impressos que demonstram a necessidade de regrar comportamentos no interior da instituição, como está demarcado pelo Primeiro Regulamento Interno, datado de 10 de março de 1920, onde constam várias orientações destinadas aos estudantes externos e internos à instituição sobre os horários das atividades, os boletins de nota e frequência, a higiene pessoal, o clube literário e os jogos atléticos.

Não obstante as limitações aqui expostas, além do Regulamento supracitado, concentraremos a análise num prospecto publicado em 1918, no Regulamento de 1920 e no Decálogo, publicado em 1925, que passa a orientar não apenas os estudantes, mas também o cidadão religioso que necessitava manter um comportamento aceitável e propositivo para o desenvolvimento social, previsto na "Lei do Governo Próprio", como consta no referido documento.

Os prospectos, etimologicamente do latim prospectus, não apenas serviam para divulgar as ações educativas aplicadas aos estudantes do Colégio, mas, sobretudo, à difusão dos princípios essenciais de ser humano que se pretendia formar por meio da educação e da fé cristã batista. Percebe-se que um dos objetivos da publicação era o de atrair potenciais clientes, ou seja, os pais de alunos, motivados, especialmente, por uma educação que valorizasse a lealdade a Deus, o intelecto e a saúde física.

Para o manuseio das fontes e extração dos significados enredados nessa figuração educacional, nos inspiramos em Aróstegui (2006), que apresenta características essenciais na análise para comportar os problemas de uma investigação científica no campo historiográ- 
fico, sendo a fiabilidade e a adequação. Podemos compreender que esses dois elementos configuram não apenas conceitos para a apropriação e a valorização do trabalho do historiador, mas, sobretudo, procedimentos essenciais para superar a ideia de "autenticidade", "veracidade" e "objetividade", tradicionalmente requeridos numa investigação científica com as características aqui definidas.

Para o autor, a fiabilidade corresponde à autenticidade, historicidade da fonte, o percurso desenvolvido, bem como a relação do produtor com o destinatário da mensagem. De maneira que a análise documental tenha por base os pressupostos imbricados naquele vestígio para assegurar, até certo ponto, uma representação da paisagem histórica correspondente às questões de pesquisa.

A análise documental orientada por Aróstegui (2006), ao lado dos conceitos eliasianos, permitiu perceber, e a estrutura da narrativa demonstrará, que a figuração institucional, objeto deste estudo, enredava um conjunto de proibições a partir não somente de um discurso de lealdade a Deus, como também de lealdade à escola, à cidade e à humanidade. Isso é o que Elias (2006) poderia chamar de "sistema de crenças", pressuposto importante para a sobrevivência social de um grupo determinado.

Os vestígios encontrados no Colégio Americano Batista compõem elementos significativos de impressos e iconografia educacional importante para futuras investigações. Contudo, não foi possível expor a massa documental disponível pelas limitações deste trabalho, mas isso pode ser facilmente constatado nos estudos de Silva (2009), Perruci et al. (2007), Sellaro (1987), Anjos (2013) e, especialmente, na pesquisa de Costa (2014), que revela um cotidiano institucional marcado por práticas esportivas e de lazer, cotejadas por incentivos e proibições.

As fontes aqui arroladas foram analisadas na perspectiva de marcos conceituais eliasianos por entendermos que "toda teoria é, por força própria, parte da inércia da construção e constituição de um objeto de pesquisa, cabendo, portanto, ao investigador, em seu esforço intelectual, dar vida à teoria e, sobretudo, movimentá-la no campo interpretativo" (SOUZA, 2009, p. 11). Desse modo, foi possível identificar que essas fontes são, inegavelmente, produtos de um saber produzido com finalidade muito específica, a de uma figuração social de base protestante que pretendia se estabelecer no campo religioso e da educação em Pernambuco.

As fontes do nosso objeto de investigação mostram com clareza uma figuração que pretendia educar por meio de dispositivos de controle, que circulavam entre estudantes e cidadãos comuns, da difusão da fé cristã no Nordeste do Brasil e do controle necessário para uma vida com Deus em seu cotidiano. Por essa razão, as orientações não se restringiam apenas aos comportamentos no interior do Colégio, em aulas, ou no momento do recreio ou nos jogos esportivos, mas, por vezes, as regras se estendiam para um nível de controle além da própria instituição educacional, cuja responsabilidade cabia aos pais, no seio da família, como podemos constatar na estrutura da narrativa a partir das reflexões eliasianas. 


\section{Os dispositivos de controle no Colégio Americano Batista}

As instituições, cada uma ao seu modo, comportam modelos fundamentais para imprimir no indivíduo, sob sua responsabilidade, as crenças, valores e códigos necessários para a manutenção de seus saberes e possível transmissão às gerações futuras. Para tanto, é necessário arcar com dispositivos de disciplinamento e controle, para que seu sistema de crenças possa ser efetivamente assegurado em meio a vários fatores sociais intervenientes e que assegurem, de certo modo, os dispositivos de distribuição e controle de poder, considerando o estabelecimento institucional com essa finalidade.

A partir dos marcos conceituais eliasianos, explicar os processos e os compromissos sociais na história das instituições educativas e da cultura escolar, como é o caso, é o que vale para compreender as transformações que levaram uma figuração específica a construir, em longo prazo, um conjunto de normas com o propósito de regular os comportamentos de indivíduos e grupos na perspectiva de difusão e transmissão de seu sistema de crenças às gerações futuras. Tomando por base esses aspectos, ao nos debruçarmos sobre as fontes aqui arroladas, a análise identificou, simultaneamente, incentivos às práticas miméticas, resguardo da polidez de condutas em jogos atléticos e controle sobre os indivíduos a partir de dispositivos publicados pela Instituição Batista.

Uma das primeiras ações do Colégio Americano Batista em direção à permissão de atividades miméticas, assim como os dispositivos de controle, se deu por ocasião da produção de um Regulamento Disciplinar que apresentava uma série de predisposições para organizar o comportamento dos estudantes, cujo registro pode ser encontrado na Ata da Junta do próprio Colégio, em 10 de março de 1920, conforme descrição e apontamentos de Perruci et al. (2007, p. 51-55).

O Regimento Disciplinar orientava estudantes externos e internos à Instituição Batista. Para os externos, a orientação visava demarcar sua condição de permanência apenas no horário marcado para o início das atividades, ou seja, pontualmente às 8 horas, "tomarem parte nos exercícios physicos" e, após as aulas, os estudantes deveriam prontamente "voltar para casa", como consta no quarto item do Regulamento para essa categoria de estudante.

Explicitamente, o Regulamento de 1920 reconhecia os benefícios higiênicos dos "jogos athleticos" e reafirmava que "O Collegio dispõe de espaçosas áreas para jogos dessa natureza, como volleyball, foot-ball, lawn-tennis [tênis no gramado] etc.", grafados dessa forma, em itálico, para realçar o que havia de mais moderno no ensinamento da instituição. Depreende-se, pela análise, que se pretendia, por vezes, provocar mudanças na estrutura social, nas relações de poder, por terem ensinamentos religiosos, e, ao mesmo tempo, predisposições modeladas pela ciência, entre a liberdade e autonomia, o que chamavam de self-control e "a natureza moral".

Com essas predisposições, os estudantes do Colégio Americano Batista eram provocados ao establishment da fé e a tomar posição de destaque em diferentes espaços sociais. É verdade que o conceito de establishment é bastante complexo, considerando o pensamento de Elias e Scotson (2000) sobre os de "dentro e de fora", especialmente seus estudos numa 
pequena comunidade e as relações de poder entre seus membros. Embora complexo, o conceito serve, por analogia, para realçar a dinâmica que se estabelecia naquele ambiente educacional e religioso. ${ }^{1}$

Considerando as declarações expressas nas fontes sob análise, depreende-se que os indivíduos que compunham o Colégio Batista pretendiam reafirmar o sentimento de establishment e o sentido de mudança na estrutura social a partir da evangelização dos princípios que norteavam os batistas e a educação escolarizada. Embora seja uma afirmação excessiva na perspectiva de que indivíduos e grupos provoquem, deliberadamente, processos sociais, tudo leva a crer que seus planos e suas ações, conforme Elias (2006), colaboram de forma cega para as mudanças em longo prazo.

Nesse sentido, vários comportamentos são recomendados no Regulamento, entre os quais podemos destacar o que trata da Sociedade Literária, o boletim, que previa o período de solicitação das notas e avaliação da conduta, disciplina, pontualidade, cooperação e dos Jogos Atléticos. Para a Sociedade Literária, no entanto, estavam previstas duas funções: o desenvolvimento das "faculdades oratórias, tomando parte em debates e torneios parlamentares", e a outra função dizia respeito "a promover o desenvolvimento physico dos associados por meio de jogos e exercícios". O Regulamento era claro em afirmar que, embora a Sociedade Literária estivesse sob o "governo do Collegio", ou seja, sob a administração política da instituição, as atividades a que se destinavam eram desenvolvidas pelos próprios estudantes para despertá-los ao self-control.

Considerando o que Elias e Dunning (1992) falam das atividades miméticas, na análise, é possível perceber que os exercícios físicos e os jogos atléticos eram permitidos e aconselhados como traços de diferenciação entre o Colégio Americano Batista e outras instituições educacionais, talvez católicas. Na perspectiva dos autores, atividades com essas características geram tensão agradável e também correspondem ao processo de desportivização de alguns passatempos das classes altas inglesas. Assim, é possível que os ensinamentos do Colégio Americano Batista pretendessem despertar o sentimento established nos estudantes ao chamar a atenção para o que acontecia nas escolas inglesas, como consta do Regulamento Disciplinar de 1920.

Nesse contexto, o Regulamento deixa claro que as atividades desenvolvidas pela Sociedade Literária, e a própria ideia de se manter no interior da instituição uma entidade como essa, deve-se ao fato de que os Estados Unidos e a Inglaterra possuíam experiências semelhantes em suas escolas, razão pela qual esses países tinham também grandes oradores. Podemos considerar que a Sociedade Literária colaborava para o que Elias (2006, p. 28) chama de "patrimônio social do saber".

1 O estudo de Elias e Scotson (2000) é sobre a comunidade fictícia de Winston Parva, onde os estabelecidos, como podemos pressupor, são os moradores mais antigos, que apresentam diferenciação dos outsiders "os de fora", apenas por esse critério, ou seja, tempo de moradia. Apesar de compartilharem das mesmas instituições educativas e religiosas, ocuparem as mesmas funções profissionais no ambiente de trabalho, estabelecidos e outsiders gozam de sentimentos de intocabilidade, não sendo recomendado brincadeiras e, sobretudo, o casamento entre seus filhos. 
Muito embora a aplicação desse conceito esteja relacionada a processos de longo prazo, os grupos sociais, na perspectiva do nosso autor, procuram resguardar uma espécie de capital para a sua sobrevivência. Assim, a partir da análise, identificamos que a Sociedade Literária materializava ideias, sentimentos e comportamentos que reproduziam as sociedades modernas de língua inglesa.

Conforme pensa Elias (2006), os símbolos linguísticos são responsáveis pela transmissão dos saberes herdados em processos sociais, o que era incentivado no colégio por meio dos "torneios parlamentares". Esses torneios, previstos como uma das atividades da Sociedade Literária, demonstram o sentido da oratória fundamental na formação humana e disseminação dos saberes. Essa também poderia ser considerada uma atividade mimética, na medida em que o que se pretendia era desenvolver o pensamento e o discurso por meio de competições e jogos.

É curioso pensar que atividades que geravam tensões agradáveis constavam no rol de práticas educativas numa instituição religiosa como o Colégio Americano Batista. Entretanto, ao analisarmos mais densamente o significado da Sociedade Literária, perceberemos que não apenas lembravam os investimentos dos colégios ingleses e americanos com traços de modernidade e incentivo ao self-control, mas também reproduziam práticas de confronto entre opositores sem, evidentemente, terem que se expressar por meio da violência, sobretudo, a violência física.

Podemos pensar que os torneios parlamentares, com os jogos atléticos, repousam na dimensão de um processo civilizacional profundamente discutido por Elias e Dunning (1992) como elementos de controle dos impulsos e, por extensão, pacificação da sociedade. Vejamos, então, como esses autores analisam a proximidade dessas duas esferas fundamentais para a pacificação social.

Neste aspecto, o regime parlamentar apresenta certas afinidades com os jogos
desportivos. Esta aproximação não é acidental. Um tipo específico de activi-
dades de lazer, como, por exemplo, a caça, o boxe, a corrida e alguns jogos
de bola, assumiu as características de desporto e, de facto, foi designado por
desporto pela primeira vez em Inglaterra, durante o século XVIII, isto é, no
mesmo período em que as antigas assembleias de estado, a Câmara dos Lordes
e a Câmara dos comuns, representando camadas da sociedade restritas e privi-
legiadas, constituíram a principal área de confronte onde se determinou quem
deveria formar governo. (ELIAS e DUNNING, 1992, p. 51).

Como podemos perceber, a análise de Elias e Dunning (1992) aproxima consideravelmente a formação do parlamento na Inglaterra e a desportivização dos passatempos como sendo processos sociais simultâneos com a mesma finalidade, embora se trate aqui de outro ambiente empírico, é claro, mas se assemelham às atividades que assumem características diferentes nas ações dos indivíduos e grupos, cotejadas pelo mesmo sentido de sublimação dos impulsos, ora a partir da oratória, no parlamento, ora na simulação dos confrontos em atividades com bola. 
Apesar do anacronismo que se resvala entre os elementos empíricos dos autores e o objeto desta investigação, nossas fontes explicitam textualmente os torneios parlamentares e os jogos atléticos que, em última instância, são produtos que revelam competição e cooperação entre adversários, semelhante situação analisada nos estudos de Elias e Dunning (1992) quanto às suas reflexões acerca do processo civilizacional, inclusive atividades que ressaltavam, segundo os autores, a delimitação territorial ou área de confronto, ou seja, as limitações geográficas e as condições éticas.

Se o Regulamento de 1920 do Colégio Americano Batista defendia as atividades desenvolvidas pela Sociedade Literária na instituição religiosa e educativa, é bem provável que as condições que fortaleciam essas ideias tenham se dado anteriormente, como podemos verificar no prospecto orientado para o ano de 1918, que conservava elementos essenciais no que diz respeito aos cuidados com o corpo, como veremos a seguir:

O Collégio tem por fim a preparação dos seus educandos para preencherem efficazmente os seus logares como cidadãos de primeira ordem. Para chegar a este resultado, trata do desenvolvimento symetrico, attingindo ao corpo físico, à intellectualidade e à natureza moral. (Prospecto, CAB, 1918, apud PERRUCI et al., 2007, p. 35).

A fonte indica o sentido de propaganda das ações e objetivos do Colégio num período bastante promissor para o campo das ciências, especialmente, as médicas. Assim, a publicação continua reafirmando e incentivando as práticas corporais, sobretudo, a ginástica sob a orientação do método sueco enquanto científico e fundamental para o equilíbrio harmônico do corpo. O texto chama a atenção para atividades realizadas à luz da ciência e para docilizar as articulações, as “juntas” corporais. Vejamos, então, o enxerto:

[...] nosso Collégio pretende adaptar os exercícios considerados mais apropriados ao clima da localidade, a saber, o systema sueco... o Collégio adopta o systema scientífico, cujos exercícios são baseados em conhecimentos anatômicos e physiológicos... os movimentos da gyminástica sueca, praticados com a devida regularidade, distendem obedientemente os músculos, tornam dóceis as juntas, dilatam o thorax, dão aos corpos desenvolvimento harmônico, sem excessos, têm ainda a virtude de corrigir certos defeitos physicos ... as aulas são obrigatórias para alunos dos cursos: Primário, Intermediário e Secundário, sendo facultativas nos demais Cursos" (Prospecto, CAB, 1918, apud PERRUCI et al., 2007, p. 35).

Por meio do Regulamento Disciplinar e, posteriormente, do Decálogo, como veremos, os agentes responsáveis pela aplicação do controle, inicialmente professores e gestores da escola e depois os pais no contexto da família, talvez pretendessem despertar a "segunda natureza" nos estudantes e futuros cidadãos na ocupação de seus espaços de poder, considerando, é claro, que o Colégio Americano Batista apresentava-se como uma instituição que tinha por finalidade "a preparação dos seus educandos para preencherem efficazmente os seus logares como cidadãos de primeira ordem" (Prospecto CAB, 1918, apud PERRUCI et al., 2007, p. 35). 


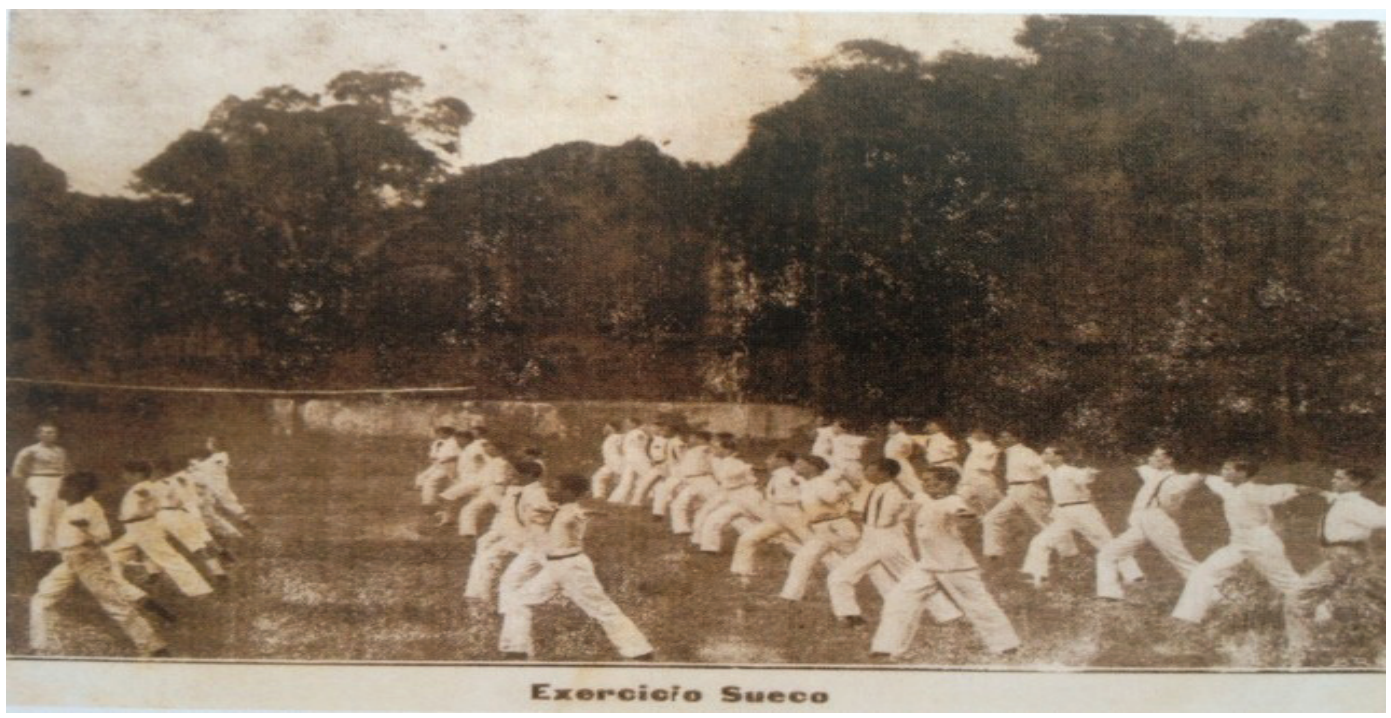

Figura 1 - Exercício Sueco

(Acervo CAB, apud PERRUCI et al., 2007, p. 35)

Desse modo, a instituição batista investia em atividades que promovessem indivíduos com sentimentos established, na medida em que estava explícita sua finalidade na formação humana, ou seja, para ocupar ambientes de destaque na sociedade. Outro aspecto a ser levado em consideração na análise é a prescrição dos exercícios físicos, que corrigiam os defeitos corporais e dilatariam o tórax, permitindo, por conseguinte, "o desenvolvimento harmônico" da composição corporal.

Com base na teoria desenvolvida por Elias e Dunning (1992), podemos compreender que o Colégio Americano Batista -, e por extensão, a própria Sociedade Literária, incentivavam a excitação agradável por meio da ginástica sueca e atividades esportivas, que tinham princípios científicos a partir da anatomia e fisiologia. Além disso, havia também a preocupação pedagógica, na medida em que os exercícios da ginástica sueca eram adaptados às peculiaridades locais, respeitando, inclusive, as predisposições climáticas.

Se por um lado, as atividades miméticas eram permitidas e aconselháveis como uma distinção educativa entre as instituições de ensino defendidas pelo Colégio Americano Batista em seu Regulamento, por outro, várias atividades e comportamentos deveriam ser proibidos e controlados em seu ambiente educacional em nome da "Lei do Governo Próprio", ou numa linguagem eliasiana, autocontrole. Nesse aspecto, as proibições ocorriam basicamente na hora do recreio onde os estudantes podiam brincar livremente no sítio, mas eram proibidos de tirar frutas, trepar nas árvores, jogar pedras e paus nas plantas e, nos feriados, os internos só poderiam ausentar-se da instituição com o acompanhamento de professores ou autorização expressa dos pais.

O self-control, escrito no Regulamento Disciplinar de 1920, tinha uma dupla função. Primeiro, expressava a necessidade de os estudantes conduzirem sua vida futura a partir 
da percepção independente e autônoma, experimentada nas inúmeras atividades realizadas pela Sociedade Literária. Segundo, para que isso ocorresse, era preciso seguir com a autonomia, mas sem perder de vista o sentido primordial desse controle, que era o de desenvolver o senso crítico e criativo para melhor servir à sociedade de seu tempo.

O Regulamento e o Decálogo são documentos produzidos e publicados em momentos diferentes da existência institucional do Colégio Americano Batista, mas compunham a mesma orientação aos estudantes. Essa orientação dizia respeito ao autocontrole emocional, a partir das experiências nos "jogos parlamentares", bem como nos "jogos athleticos", o que permitia o desenvolvimento da "intellectualidade e à natureza moral", conforme descrição textual da fonte.

Nesse sentido, é importante pensar como Elias e Dunning (1992), que refletiram com bastante densidade o processo de desportivização dos passatempos ingleses, ao mesmo tempo em que o parlamento passa a ter um papel fundamental na pacificação dos impulsos. Assim, fica clara a intenção da proposta educacional dos batistas: desenvolver a oratória e a harmonia corporal por meio de debates e exercícios físicos, cientificamente orientados pela ginástica sueca, bem como os jogos atléticos, que ocupavam uma tipologia do tipo mimética.

Elias e Dunning (1992), ao analisarem o conceito de mimese apresentado por Aristóteles, afirmam que o filósofo cunhou esse termo grego no sentido do imitatio -imitação -, cuja estética de sua filosofia pressupõe a verossimilhança da vida ordinária. De modo que a arte, especialmente o teatro grego, impulsionava a catarse dos dramas da vida real na medida em que a emoção aflorava a partir da interpretação dos atores nas tragédias. Contudo, na acepção eliasiana, as atividades miméticas, como as artes, o teatro e os esportes, além de comportar nexos fundamentais na representação da vida social, os indivíduos que delas tomam parte buscam tensões agradáveis.

Sob a forma de factos de lazer, em particular os da classe mimética, a nossa sociedade satisfaz a necessidade de experimentar em público a explosão de fortes emoções - um tipo de excitação que não perturba nem coloca em risco a relativa ordem da vida social, como sucede com as excitações de tipo sério. (ELIAS e DUNNING, 1992, p. 112).

Como é possível verificar, os autores reconhecem que a explosão emocional presente nas atividades miméticas não colocam em risco o indivíduo nem "a relativa ordem social", porque é uma explosão com finalidade específica na busca pelo prazer e pela tensão agradável, experimentada a partir de regras específicas que envolvem cooperação, superação de limites, controle e autocontrole.

Podemos perceber, mediante as fontes consultadas, que o Colégio Americano Batista, como configuração educacional, buscava por meio das ações da Sociedade Literária, por exemplo, o refinamento da conduta de seus estudantes, promovendo os torneios parlamentares e os jogos atléticos, que correspondiam aos debates e às competições de futebol, voleibol e tênis. Podemos pressupor que os torneios e os jogos serviam de técnica de sublimação dos impulsos revertidos em cooperação e/ou tensão entre opositores, mas em constante 
interdependência funcional, na busca da excitação agradável, conforme Elias e Dunning (1992) ao tratarem, em seus estudos, sobre as atividades miméticas.

Mesmo compreendendo que os jogos atléticos forneciam o ingrediente de satisfação e prazer ao estudante, o Colégio não se comprometia em "reformar" o menino que ali chegasse, mas firmava compromisso social em discipliná-lo, e não tendo êxito nesse processo, prosseguiria com a sua eliminação institucional para não contaminar os de melhor comportamento, ou seja, os bons meninos, que à luz dos dispositivos deveriam se adequar, controlar o comportamento impulsivo contrário ao bem. Assim, segue o enxerto do Regulamento:

\begin{abstract}
Não prometemos reformar qualquer menino que nos for confiado. Um compromisso, porém, tomamos sincera e firmemente: o de fazer tudo que estiver ao nosso alcance para conseguir disciplina-lo. Não podendo, eliminaremos o insubordinado. É melhor eliminar um menino mau do que permittir que ele contamine os bons. [...] disciplinar qualquer menino cujos sentimentos não forem indiferentes aos impulsos do bem. (Regulamento, CAB, 1920, apud PERRUCI, et al., 2007, p. 54).
\end{abstract}

O Regulamento continuava solicitando a colaboração dos pais no sentido de disciplinar os filhos, porque todo o menino que, à luz dos ensinamentos ali prestados, se mantivesse um sentimento de impulsividade contrário ao bem, seria expulso. Logo, percebe-se que o desejo manifesto da Instituição Batista era o de controlar os impulsos emocionais não condizentes com o previsto naquele ambiente religioso e educacional.

Nesse contexto, a figuração batista demonstrava bastante clareza quanto à sua responsabilidade na condução dos estudantes, e buscava inspiração em revistas especializadas, conforme consta do Regulamento, em que se associa conceitualmente a uma revista de educação para reafirmar a necessidade dos pais cooperarem com a escola no "fim comum de educar os seus filhos" porque "para a escola produzir todos os efeitos úteis, precisa, indispensavelmente, da cooperação cordial da família, do seu apoio moral, constante, effectivo, manifesto [...]"' (Regulamento CAB, 1920, apud PERRUCI, et al. 2007, p. 25).

Entre as publicações com vistas à orientação e controle dos impulsos do mal em detrimento aos impulsos do bem, consta o Decálogo em 1925, que passou a ser, como era seu objetivo, o principal mecanismo de orientação e controle nesse período, cuja reprodução de seu conteúdo também pode ser lida originalmente nos prospectos igualmente publicados para a sociedade pernambucana, em pesquisas no campo da historiografia da educação, bem como na publicação do centenário da instituição, conforme está descrito em Perruci et al. (2007), nossa principal fonte de consulta.

O Decálogo é constituído por um curto preâmbulo que trata das "leis fixas" que governam a vida em sociedade e se apresenta como "excelente código de moral", devendo ser assimilado e constar na prática diária do indivíduo, considerando a necessidade de cooperação para o bem-estar de todos. Pelo que compreendemos, a essência do Decálogo consiste em reafirmar a interdependência funcional dos established, especialmente entre os estudantes, que devem manter sempre em mente a cooperação para o bem da instituição e do país. 
A fonte pressupõe também uma leitura na primeira pessoa do singular, "eu”, em detrimento de "nós" e "ele", em que o indivíduo se declara consciente dos princípios a serem seguidos, numa espécie de exercício de autocontrole, autocoerção, e que precisa reafirmar a concordância às leis expressas. Se por um lado o Regulamento tece comentários mais abrangentes, situando o estudante nos ambientes e procedimentos institucionais, por outro, em linhas gerais, pela própria denominação, o Decálogo diz respeito aos mandamentos de Deus escritos por Moisés em duas tábuas. Por analogia, o Colégio Americano Batista prescreve um conjunto de dez regras a serem seguidas pelos seus estudantes, são elas:

I - Da Saúde; II- Do Governo Próprio; III - Da Confiança Própria; IV - Da Confiança nos Outros; V - Do Cavalheirismo no Jogo; VI - Do Devir; VII - Da Aptidão; VIII - Da Cooperação; IX - Da Bondade; X - Da Lealdade. (Decálogo CAB, 1925, apud PERRUCI et al., 2007, p. 58-60).

Silva (2009) analisa a décima orientação, a Lei da Lealdade, em que os estudantes deveriam ter primeiramente para com Deus, à humanidade, à família e ao próprio colégio, como forma de expressar os compromissos anteriormente assumidos, os princípios e as regras estabelecidas na instituição de ensino. Por sua vez, Costa (2014) analisa, a partir do Decálogo, os aspectos referentes às atividades de lazer, especialmente as permissões e proibições impostas naquele cotidiano educacional, o que se aproxima consideravelmente dos pressupostos deste artigo.

Assim, em conformidade ao que está posto no Decálogo, duas leis são fundamentais para efeito da análise, sendo as leis “do Governo Próprio e do Cavalheirismo no Jogo". Essas duas orientações permitem verificar com propriedade as intenções do referido colégio na direção do controle e dos compromissos sociais a partir da fé e dos princípios educativos almejados na sublimação dos desejos do mal que poderiam atingir o estudante.

Embora o fundamento do objeto de controle dos impulsos fosse de finalidade religiosa, ressaltam-se os aspectos sociais, de convívio diário, no ambiente escolar, enquanto elementos importantes para a manutenção institucional e para atender aos seus objetivos, o que Elias e Dunning (1992) chamariam de domínio das relações interpessoais, por isso a necessidade do desenvolvimento do autocontrole, inicialmente, no conteúdo do Regulamento self-control, podendo ser analisado em dois prismas, como vimos, e do Governo Próprio, que expressa com mais firmeza a meta social a ser atingida pela instituição, por isso que o estudante também teria que assimilar o pressuposto de que, somente governando a si mesmo, poderia servir e assumir postos de comando na sociedade, como explicitado no self-control, como um established, provavelmente.

O preâmbulo da Lei do Governo Próprio diz textualmente que um indivíduo que não se governa, não poderia servir ao seu país, o que lembra a ideia do self-control, publicado no Regulamento de 1920. Nessa direção, essa lei exigia que o estudante proferisse as seguintes palavras:

1 - Governarei minha língua e não lhe permitirei palavras mesquinhas, vulgares ou profanas; 2 - Governarei meu temperamento e não me zangarei quando as 
pessoas ou as cousas não me agradarem; 3 - Governarei meus pensamentos e não deixarei um desejo tolo estragar um propósito sábio. (Decálogo $\mathrm{CAB}$, 1925, apud PERRUCI et al. 2007, p. 59).

Para Elias e Dunning (1992), o autocontrole ou a autocoerção é o mais decisivo do ponto de vista civilizacional, porque o próprio indivíduo internaliza e controla os elementos que contrariam sua relação com os outros, os desejos "nefastos", as atitudes e, por conseguinte, a repulsa pela violência física. Nessa perspectiva, os educadores do Colégio não pretendiam "reformar" os estudantes, mas inibir os impulsos do mal, impondo as regras presentes no Decálogo.

Não obstante o controle dos impulsos presente na Lei do Governo Próprio, outra orientação também decisiva e ao mesmo tempo conciliadora, pela complexidade das tensões necessárias ao desenvolvimento do esporte moderno, estava no conteúdo da Lei do Cavalheirismo no Jogo, que pressupunha a necessidade de despertar nos estudantes o sentimento de distinção, gentileza e nobreza em seus planos e ações quando a realização dos torneios parlamentares e, sobretudo, nos jogos atléticos.

A Lei do Cavalheirismo no Jogo diz respeito à força física desenvolvida por meio de jogos atléticos, praticados sem fraudes, no sentido de formar cidadãos para servir de maneira eficiente ao seu país. As orientações chamam a atenção para o prazer que os jogos devem provocar nos indivíduos, mantendo-se sempre o nível de satisfação entre todos que tomam parte. Sendo assim, o estudante declarava o que se segue:

\footnotetext{
1 - Não usarei de meios ilícitos no jogo. Se eu não jogar honestamente, o vencido perderá o prazer do jogo, o vencedor perderá o seu respeito próprio e o jogo se tornará uma coisa baixa e cruel; 2 - Tratarei o meu adversário com cortesia; 3 - Se eu jogar com um grupo, jogarei, não para minha glória, mas pelo sucesso do team e pelo prazer do jogo. (Decálogo CAB, 1925, apud PERRUCI et al. 2007, p. 59).
}

Desse modo, o Colégio e seus dispositivos podem ser analisados como "agências controladoras construídas" (ELIAS, 1993, p. 237), em que se esperava dos próprios estudantes a lealdade em observar o comportamento do outro, numa espécie de autocontrole e controle de uns sobre os outros, porque o que se esperava era a seguinte declaração: "Serei leal ao meu Collegio. Lealmente obedecerei, e auxiliarei outros alunos a obedecer às regras que contribuam para o bem-estar de todos" (Decálogo CAB, 1925, apud PERRUCI et al., 2007, p.60). Assim, há de se considerar, no entanto, que as funções psicológicas entre o "id", o "ego" e o "superego", ora parcialmente conflitantes, ora em cooperação, segundo Elias (1993), unidos aos ambientes de controle, como é o caso da Instituição Batista, têm considerável importância na compreensão das decisões tomadas pelos indivíduos na direção de sua conduta, por conseguinte, desenvolvendo o autocontrole em longo prazo.

Nessa perspectiva, Governo Próprio e o Cavalheirismo no Jogo compõem faces da tensão estabelecida na estrutura e funções psicológicas, bem como na estrutura da instituição de controle, senão para "reformar" o estudante, pelo menos para disciplinar os "impul- 
sos contrários ao bem", controlar os "desejos tolos", que poderiam desvirtuar o estudante dos grandes propósitos do conhecimento. Assim, a principal finalidade das orientações postas no Governo Próprio e do Cavalheirismo no Jogo era imprimir a distinção e a gentileza para manter o nível de satisfação social na atividade entre adversários e, para tanto, era necessário controlar impulsos desagradáveis, que pudessem levar aos atos "vulgares e profanos". Além disso, a observância dessas leis poderia levar o estudante a servir a Deus, ao país e ao seu Colégio.

Para Elias e Dunning (1992), as práticas miméticas resguardam tensão de forma agradável e que são almejadas pelos indivíduos, sem trazer prejuízo para si ou para os outros, inclusive sem que seja revertido em atos violentos, embora, em alguns casos, possamos assistir em partidas de futebol o que os autores chamam de fenômeno hooliganismo, em que há destruição e desagregação, assumindo, portanto, tensões com forte componente étnico-racial.

As leis do Governo Próprio e do Cavalheirismo no Jogo pretendiam inibir impulsos que levassem aos extremos emocionais, às tensões sérias, evitando, por seu turno, possíveis atitudes violentas. Dessa forma, os dispositivos tentavam provocar no estudante o sentimento de repugnância e repulsa em relação à violência, que, mesmo perdendo no jogo, deveria manter a cordialidade junto aos adversários.

O movimento que ocorre dentro do indivíduo a partir das funções psicológicas e das relações entre paixões e sentimentos demandados no cotidiano institucional faz que sejam materializados, inconscientemente, comportamentos mais gentis e polidos, reduzindo, consideravelmente, os impulsos. Desse modo, pelo que compreendemos em Elias (1993), tanto as estruturas e funções psicológicas como os relacionamentos individuais e sociais são mutáveis, embora isso só seja perceptível empiricamente e com análise em longo prazo.

\section{CONSIDERAÇÕES FINAIS}

Para atender ao escopo do dossiê relativo às pesquisas fundamentadas na perspectiva de Norbert Elias, este artigo procurou analisar os dispositivos que pretendiam controlar os impulsos dos estudantes internos e externos ao Colégio Americano Batista, sediado na cidade do Recife, a partir de 1906. Essa é uma instituição centenária que deve resguardar um campo de memória em meio a uma massa documental significativa para pesquisas em diferentes áreas do conhecimento, inclusive na dimensão sociológica que fundamenta este dossiê. Assim, procedemos à análise em torno dos conceitos eliasianos acerca de informações relativas às práticas educativas, sobretudo, os "jogos parlamentares e jogos atléticos" destinados, inicialmente, aos estudantes do sexo masculino.

É importante frisar que a Missão Batista do Norte do Brasil só autorizou matrículas das moças batistas a partir de 1916. Antes disso, os níveis de ensino estavam apenas destinados aos meninos. Nesse sentido, os dois instrumentos que apontam para os dispositivos de controle são posteriores à participação de meninas no mesmo ambiente institucional dos meninos, mas não no ambiente de educação formal. 
De acordo com as fontes, as moças batistas dispunham de aulas para preparação de atividades cristãs junto às "Igrejas, uma vez que no Seminário não podia tê-las como alunas, pois era um estabelecimento masculino" (PERRUCI et al., 2007, p. 41). Com isso, queremos dizer que os dispositivos foram instituídos independentemente das relações de gênero na instituição batista, pois não se tem qualquer referência à proibição e controle em virtude da convivência entre os sexos.

Contraditoriamente, num ambiente onde passaram a conviver, de algum modo, outsiders e established, era necessário algum tipo de regramento, não só pelos aspectos que envolviam meninos e meninas, na perspectiva de proximidade entre os sexos, o que o podemos supor, mas, sobretudo, no lugar que cabia aos meninos internos e externos uma vez que, conforme documentado, se tratava de um "estabelecimento masculino".

A partir das fontes, a análise identifica os compromissos sociais assumidos no interior da instituição em relação à formação educacional, à promoção e difusão do protestantismo, bem como a lealdade para com Deus, o desenvolvimento da cidade e do país. Esses compromissos também são declarados nos principais dispositivos de divulgação e de controle do Colégio Batista, nos prospectos, no Regulamento e no Decálogo.

À primeira vista, são documentos relativamente comuns e previsíveis, considerando uma instituição protestante, mas, quando nos debruçamos mais densamente na análise, verificamos dispositivos de controle e de permissão de práticas bastante avançadas para a época, como a ginástica sueca e jogos parlamentares e atléticos, o que reposiciona a referida instituição educacional como uma das inovadoras na educação dos meninos, desde o Jardim da Infância em 1906, e posteriormente das meninas, a partir de 1916.

\section{REFERÊNCIAS}

ANJOS, Maria de Lourdes Porfírio Ramos Trindade dos. Educação feminina batista no Nordeste: A ação educacional de Martha Elizabeth Hairston no Seminário de Educadoras Cristãs (1953-1979). Tese (Doutorado em Educação). Faculdade de Educação, Universidade Federal de Uberlândia, Uberlândia, 2013.

ARÓSTEGUI, Júlio. A Pesquisa histórica: Teoria e método. Trad. Andréa Dora. Bauru, SP: Edusc, 2006.

CALVANI. Carlos Eduardo B. A educação no projeto missionário do protestantismo no Brasil. Rev. Pistis Prax., Teol. Pastor., Curitiba, v. 1, n. 1, p. 53-69, jan./jun. 2009.

CORDEIRO, Ana Lúcia. Religião e projetos educacionais para a nação: A disputa entre metodistas e católicos na primeira república brasileira. Belo Horizonte, v. 4, n. 7, p. 110124, dez. 2005.

COSTA, Marcos André Nunes. A educação para e pelo lazer no Colégio Americano Batista: Uma análise dos dispositivos de controle das emoções à luz da teoria elisiana 
(1960-1990). Tese (doutorado em Educação). Centro de Educação, Universidade Federal de Pernambuco. Recife, 2014.

ELIAS, Norbert. Introdução à sociologia. Trad. Maria Luísa Juventa Ferreira. Lisboa: Edições 70, 1970.

. DUNNING, Eric. A busca da excitação. Lisboa: Difel, 1992.

. O Processo Civilizador: Uma história dos costumes. Rio de Janeiro: Jorge Zahar Ed., 1994, 1v.

. O Processo Civilizador: Formação do Estado e Civilização. Rio de Janeiro: Jorge Zahar Ed.,1993, 2v.

. SCOTSON, John L. Os estabelecidos e os outsiders: Sociologia das relações de poder a partir de uma pequena comunidade. Rio de Janeiro: Jorge Zahar, 2000.

LUCENA, Ricardo de F. Norbert Elias: Corpo, educação e processos civilizadores. In: Anais. X Simpósio Internacional Processo Civilizador, abr. 2007. Campinas, SP, Brasil. Disponível em: http://www.uel.br/grupo-estudo/processoscivilizadores/portugues/sitesanais/anais10/Artigos_PDF/Ricardo_Lucena.pdf. Acesso em: 18 abr. 2014.

MARTINS, Luiz Candido; CARDOSO, Luiz de Souza. A dimensão civilizatória da presença do americano no Brasil: Tecnologia, educação e religião. In. Anais. IX Simpósio Internacional Processo Civilizador: Tecnologia e Civilização, nov. 2005. Ponta Grossa, PR, Brasil. Disponível em: http://www.pg.utfpr.edu.br/ppgep/Ebook/cd_Simposio/artigos/ mesa_debates/art18.pdf. Acesso em: 27 jul. 2017.

MESQUITA, Antônio N. de. História dos batistas do Brasil: de 1907 até 1935. II Vol. Casa Publicadora Batista, 1940.

OLIVEIRA, Lílian Sarat de. Educadoras religiosas no Brasil do século XIX nos caminhos da civilização. In.: Anais. XII Simpósio Internacional de Processo Civilizador; Civilização e contemporaneidade, nov. 2009. Recife-PE, Brasil. Disponível em: http://www. uel.br/grupo-estudo/processoscivilizadores/portugues/sitesanais/anais 12/artigos/pdfs/ comunicacoes/C_Oliveira3.pdf. Acesso em: 27 jul. 2017.

PERRUCI, Glaucília, et al. História do CAB Recife: "Eternamente nosso bem" - Uma linda história de amor com muitas histórias. CEPE, 2007.

SARAT, Magda e SARAT, Lílian. História de viajantes e suas missões civilizadoras. In. Anais. X Simpósio Internacional de Processo Civilizador. Abr. 2007, Londrina, PR. Brasil. Disponível em: http:/www.uel.br/grupo-estudo/processoscivilizadores/portugues/ sitesanais/anas8/artigos/MagdaSarat.pdf. Acesso em: jul. 2017.

SELLARO, Lêda Rejane Accioly. Educação e religião: Colégios protestantes em Pernambuco na década de 20. Dissertação (Mestrado em Educação). Centro de Educação, Universidade Federal de Pernambuco, Recife, 1987. 
SILVA, Sandra Cristina da. Educação de papel: Impressos protestantes educando mulheres. Dissertação (Mestrado em Educação). Centro de Educação, Universidade Federal de Pernambuco, Recife, 2009.

SOUZA, Edilson Fernandes de. Norbert Elias: uma teoria desconectada à realidade brasileira, balançando o chicote. In. SOUZA, Edilson Fernandes de. SIMÕES, José Luís. LUCENA, Ricardo de Figueiredo (Orgs.). Escritos a partir de Norbert Elias. Recife: Ed. Universitária da UFPE, 2009.

\section{DADOS DOS AUTORES}

\section{EDILSON FERNANDES SOUZA}

Doutor em Educação Física/Estudos do Lazer pela Universidade Estadual de Campinas. Pós-doutor em Sociologia pela Universidade do Porto-Portugal. Docente do Programa de Pós-Graduação em Educação/Núcleo de Teoria e História da Universidade Federal de Pernambuco. Recife/PE - Brasil. edilson@ufpe.br

\section{JOSÉ LUÍS SIMÕES}

Doutor em Educação pelo Programa de Pós-Graduação em Educação da Universidade Metodista de Piracicaba. Docente do Programa de Pós-Graduação em Educação/Núcleo de Teoria e História da Universidade Federal de Pernambuco. Recife/PE - Brasil. joseluis2711@ yahoo.com.br

\section{MARCOS ANDRÉ NUNES COSTA}

Doutor em Educação pelo Programa de Pós-Graduação em Educação/Núcleo de Teoria e História pela Universidade Federal de Pernambuco. Docente do Departamento de Educação Física da Universidade Federal Rural de Pernambuco. Recife/PE - Brasil. marcos. nunes@ufrpe.br

Submetido em: 20-8-2017

Aceito em: 6-11-2017 